- Letter

\title{
Clinical Implication of Korean Dry Sauna Therapy
}

\author{
Teruhiko Imamura* \\ Second Department of Medicine, University of Toyama, Toyama, Japan
}

\section{To the editor}

I would like to congratulate Choi et al. ${ }^{1)}$ for their successful study on Korean dry sauna therapy where the health-related quality of life of obese people had improved without any adverse events. The therapy included 15 minutes of dry sauna at $90^{\circ} \mathrm{C}$, twice daily for 4 consecutive days. Given our experience of Japanese dry sauna therapy in patients with advanced heart failure, ${ }^{2)}$ I have several concerns regarding their protocol and future perspectives.

In our Japanese prospective randomized control trial, ${ }^{2)}$ we performed Waon therapy with 15 minutes of dry sauna at $60^{\circ} \mathrm{C}$, once daily for 10 days. While the frequency of twice daily might be more effective than once daily, it might reduce the participants' adherence. An explanation of the implications of a twice-daily protocol would be helpful. The sauna temperatures were also different between the two studies $\left(90^{\circ} \mathrm{C}\right.$ versus $\left.60^{\circ} \mathrm{C}\right){ }^{1,2)}$ It would be interesting to compare the outcomes stratified by temperature settings.

The therapeutic effects on the hemodynamics and autonomic nervous systems would be evident immediately, ${ }^{3)}$ but it might be weeks or months until the metabolic benefits can be enjoyed. Long durations of dry sauna therapy may be required to assess its implications for obesity-related metabolic diseases.

Finally, as the authors stated in the limitations section, ${ }^{1)}$ ob-

jective parameters might be useful for quantifying the impact of dry sauna therapy on the quality of life, including blood catecholamine levels and heart rate variability. ${ }^{3)}$

\section{CONFLICT OF INTEREST}

No potential conflict of interest relevant to this article was reported.

\section{ORCID}

Teruhiko Imamura: https://orcid.org/0000-0002-7294-7637

\section{REFERENCES}

1. Choi HS, Kwon H, Cho KH, Thuc LC, Park SY, Kim NH, et al. Repeated dry sauna therapy improves quality of life in obese Korean people. Korean J Fam Med 2020;41:312-7.

2. Tei $C$, Imamura $T$, Kinugawa $K$, Inoue $T$, Masuyama $T$, Inoue $\mathrm{H}$, et al. Waon therapy for managing chronic heart failure: results from a multicenter prospective randomized WAONCHF study. Circ J 2016;80:827-34.

3. Imamura T, Kinugawa K, Nitta D, Komuro I. Real-time assessment of autonomic nerve activity during adaptive servo-ventilation support or Waon therapy. Int Heart J 2016;57:511-4.

Received: March 25, 2020, Accepted: June 4, 2020

*Corresponding Author: Teruhiko Imamura https://orcid.org/0000-0002-7294-7637

Tel: +81-76-434-2281, Fax: +81-76-434-2281, E-mail: teimamu@med.u-toyama.ac.jp 